\title{
Body language
}

Citation for published version (APA):

Alleva, J. M., Martijn, C., Jansen, A., \& Nederkoorn, C. (2014). Body language: affecting body satisfaction by describing the body in functionality terms. Psychology of Women Quarterly, 38(2), 181-196.

https://doi.org/10.1177/0361684313507897

Document status and date:

Published: 01/06/2014

DOI:

10.1177/0361684313507897

Document Version:

Publisher's PDF, also known as Version of record

Document license:

Taverne

Please check the document version of this publication:

- A submitted manuscript is the version of the article upon submission and before peer-review. There can be important differences between the submitted version and the official published version of record.

People interested in the research are advised to contact the author for the final version of the publication, or visit the DOI to the publisher's website.

- The final author version and the galley proof are versions of the publication after peer review.

- The final published version features the final layout of the paper including the volume, issue and page numbers.

Link to publication

\footnotetext{
General rights rights.

- You may freely distribute the URL identifying the publication in the public portal. please follow below link for the End User Agreement:

www.umlib.nl/taverne-license

Take down policy

If you believe that this document breaches copyright please contact us at:

repository@maastrichtuniversity.nl

providing details and we will investigate your claim.
}

Copyright and moral rights for the publications made accessible in the public portal are retained by the authors and/or other copyright owners and it is a condition of accessing publications that users recognise and abide by the legal requirements associated with these

- Users may download and print one copy of any publication from the public portal for the purpose of private study or research.

- You may not further distribute the material or use it for any profit-making activity or commercial gain

If the publication is distributed under the terms of Article $25 \mathrm{fa}$ of the Dutch Copyright Act, indicated by the "Taverne" license above, 


\title{
Body Language: Affecting Body Satisfaction by Describing the Body in Functionality Terms
}

\author{
Jessica M. Alleva', Carolien Martijn', Anita Jansen', \\ and Chantal Nederkoorn'
}

\begin{abstract}
With the current studies, we aimed to improve body satisfaction by inducing a functionality-based focus on the body. Objectification theory was used as a guiding framework for this approach. In Study I, 59 female and 59 male undergraduates and, in Study 2, 118 women between the ages of 30 and 50 years completed a writing assignment to experimentally manipulate their body focus. The writing assignment instructions were to describe what one's body can do (functionality focus) or what one's body looks like (appearance focus); a control writing task was also included. Functionality and appearance satisfaction, as well as global self-esteem, were measured at baseline, on test-day, and at a I-week follow-up. In Study I, male undergraduates in the functionality condition experienced an increase in functionality satisfaction from baseline to test-day; female undergraduates in the appearance condition experienced a decrease in functionality satisfaction both from baseline to test-day and from baseline to follow-up. In Study 2, women in the functionality condition experienced an increase in functionality satisfaction from baseline to follow-up. The current studies are the first known to experimentally manipulate the functionality-based approach to the body and to investigate its effects on body image-serving to suggest perceived functionality as a potentially fruitful focus for further research and intervention.
\end{abstract}

\section{Keywords}

body image, objectification, functionality, instrumentality, physical appearance, body awareness, age differences, self-esteem

The majority of women are dissatisfied with their bodies and when asked about the specific source of body dissatisfaction, most women point to body weight and shape (Garner, 1997; Tiggemann, 2004). Body dissatisfaction has become second nature to women, so much so that it has been termed the "normative discontent" (Rodin, Silberstein, \& Striegel-Moore, 1984). Importantly, discontent about one's body is neither a harmless nor a trivial discontent: Body dissatisfaction has been associated with low self-esteem (Cash \& Pruzinsky, 2002a), depression (Paxton, Neumark-Sztainer, Hannan, \& Eisenberg, 2006), social anxiety (Cash \& Fleming, 2002a), and diminished quality of life (Cash \& Fleming, 2002b). Further, body dissatisfaction has been identified as a main causal and maintenance factor in eating disorders and body dysmorphic disorders (Cooley \& Toray, 2001; Stice, 2002). Considering the serious consequences of body dissatisfaction on well-being, it is imperative to develop novel strategies to ameliorate it. Accordingly, our aim with the present studies was to develop an innovative technique to improve body satisfaction, namely, by focusing on the functionality of the body. The theoretical framework for this approach stems from objectification theory (Fredrickson \& Roberts, 1997) - one of the most researched theories related to the body image of women.

\section{Objectification Theory}

Objectification theory posits that, in Western culture, girls and women are judged and valued mainly for their appearance rather than for their internal qualities (Fredrickson \& Roberts, 1997). Central to the objectification theory is the experience of sexual objectification. A woman is sexually objectified any time her body (parts) or sexual functions are seen as separate from her person, are seen as reflecting who she really is, or are "reduced to the status of mere instruments" (Fredrickson \& Roberts, 1997, p. 175) for the pleasure of others (Bartky, 1990). In other words, when a woman is sexually objectified, she is seen as less fully human. For example, studies have shown that when focusing on a woman's appearance, rather than on her personality, the degree of human nature assigned to her may be diminished (the attribution of

\footnotetext{
'Department of Clinical Psychological Science, Maastricht University, Maastricht, The Netherlands

\section{Corresponding Author:}

Jessica M. Alleva, Department of Clinical Psychological Science, Maastricht University, P.O. Box 616, 6200 MD Maastricht, The Netherlands.

Email: Jessica.Alleva@maastrichtuniversity.nl
} 
human nature helps people distinguish between humans and objects; Haslam, Loughnan, \& Holland, 2013; Heflick \& Goldenberg, 2009; Heflick, Goldenberg, Cooper, \& Puvia, 2011; Loughnan \& Haslam, 2007; Vaes, Paladino, \& Puvia, 2011). Sexual objectification may be present in social interactions (e.g., as when a woman is the subject of a "cat call") and is omnipresent in mainstream media, where women are often portrayed in a sexually explicit, submissive manner (Halliwell, Malson, \& Tischner, 2011).

Another central tenet of objectification theory is selfobjectification, women's internalisation of the observer's perspective toward their own bodies (Fredrickson \& Roberts, 1997). Within the cultural milieu of sexual objectification, where women's bodies are viewed as objects (Bernard, Gervais, Allen, Campomizzi, \& Klein, 2012; Gervais, Vescio, Förster, Maass, \& Suitner, 2012), women are socialised to see their own bodies as objects, too. For instance, throughout a woman's life, investment in her appearance will be reinforced (e.g., through receiving attention for wearing revealing clothing or by being praised for losing weight). Again, this selfobjectification may be strengthened by the social environment (e.g., getting honked at by a driver in a passing car; Kozee, Tylka, Augustus-Horvath, \& Denchik, 2007) and by the media (e.g., through the depiction of the thin ideal whereby slim, attractive women are depicted as happy and successful; Tolman \& Debold, 1994). As a result of being sexually objectified, and of seeing their own bodies as aesthetic objects, women inevitably learn to focus predominantly on the appearance of their bodies (Fredrickson \& Roberts, 1997). Furthermore, women may experience anxiety and body shame (when the body does not measure up to unrealistic cultural standards of appearance), which may ultimately contribute to the development of depression, sexual dysfunction, and even eating disorders (see Fredrickson \& Roberts, 1997, for an overview). These relations have been confirmed by empirical tests of the objectification theory (e.g., Tiggemann \& Williams, 2011) as well as by a comprehensive review of over a decade of research on objectification (Moradi \& Huang, 2008).

\section{Self-Objectification and Body Dissatisfaction}

Given the relations between self-objectification, body shame, and eating disorders, it seems logical that self-objectification is also closely related to body dissatisfaction. Indeed, this appears to be the case. To take a few key examples, selfobjectification has been significantly correlated with measures of body dissatisfaction and negative body image (Myers \& Crowther, 2007; Noll \& Fredrickson, 1998). Moreover, Myers and Crowther (2007) found evidence for the mediating role of self-objectification between thin-ideal internalisation and body dissatisfaction. In other words, in women who internalise the thin-ideal, evaluating the body predominantly for its appearance may lead to body dissatisfaction. In addition, in an experiment by Quinn, Kallen, and Cathey (2006), participants tried on either a swimsuit or a sweater in a private dressing room with a full-length mirror. Here, trying on a swimsuit was hypothesised to induce self-objectification. After changing back into their regular clothing, participants completed a word-stem completion task and then wrote down their thoughts for several minutes. The results showed that women who tried on a swimsuit experienced more body shame and defined their bodies more by appearance compared to women who tried on a sweater. Further, these women also demonstrated more body-related thoughts, such as "I need to get in better shape" or "My body has gone downhill since I came to college" (p. 871). The authors concluded that engaging in self-objectification induced body shame and caused women to have more (negative) body-related thoughts, even after the experimental manipulation was over.

\section{Body Functionality: An Alternative to Body Appearance}

As Fredrickson and Roberts (1997) proposed, selfobjectification necessitates a predominant focus on the appearance of the body. Research has shown that, through this predominant focus on appearance, women may eventually separate themselves from their bodily functioning (Moradi \& Huang, 2008; Roberts \& Waters, 2004). In other words, their experience of their bodies becomes more about "How do I look?" than about "How do I feel?" and "What am I capable of?" (Roberts \& Waters, 2004). This shift is important, because bodily functioning comprises the unobservable dimension of the body (e.g., health, fitness, physical strength) that forms a substantial part of the experience of the body (Franzoi, 1995; Franzoi \& Shields, 1984; Fredrickson \& Roberts, 1997). In comparison to body appearance, bodily functioning has been scarcely investigated (Cash \& Pruzinsky, 2002b; Franzoi, 1995). Considering the negative consequences of viewing the body as an aesthetic object and focusing on its appearance, it is imperative to investigate the alternative, focusing on bodily functioning. In our studies, we termed bodily functioning body functionality, and we examined whether focusing on body functionality, as opposed to focusing on body appearance, can improve body satisfaction.

\section{Conceptualisation of Body Functionality}

To date, body functionality has most often been conceptualised as related either to the fitness of the body or to its internal biological functioning. For instance, in the validation of the Body Esteem Scale (BES), Franzoi and Shields (1984) identified three body esteem dimensions. Two of these dimensions were related to appearance (Sexual Attractiveness and Weight Concern in women; Physical Attractiveness and Upper Body Strength in men). The third dimension, Physical Condition, was related to body functionality and constituted stamina, strength, and agility. Further, Avalos and Tylka (2006) conceptualised body functionality as the internal signals and functions of the body, such as feelings of 
fullness or hunger cues. In addition, Avalos, Tylka, and Wood-Barcalow $(2005$, p. 286) identified the "respect of the body by attending to its needs and engaging in healthy behaviours" as one of the main components of positive body image. Attending to this aspect of positive body image necessitates an emphasis on body functionality. Although these studies conceptualised body functionality in terms of fitness or internal biological functioning, it is important to note that the current studies will extend upon this conceptualisation of body functionality by including aspects such as the body's skills (e.g., drawing, playing an instrument) or the ways in which the body may interact with others (e.g., holding hands, body language).

\section{Current Evidence for Body Functionality}

Despite the scarcity of body functionality research, several studies do suggest that focusing on body functionality may benefit body image. For instance, Avalos and Tylka (2006) tested a model of intuitive eating in two samples of undergraduate women. In both samples, their model demonstrated that focusing on body functionality (here, how the body functions and feels internally), rather than on body appearance, was related to more positive feelings toward the body and to greater body appreciation. In addition, focusing on body functionality was related to healthier eating behaviour, namely, to intuitive eating (i.e., eating in response to internal physiological cues, rather than in response to internal emotional cues or external environmental cues; Tylka, 2006). Avalos and Tylka even stressed that focusing on body functionality, rather than focusing on looking attractive for others, should be encouraged to promote a healthier relationship with the body. To provide a better understanding of positive body image, Wood-Barcalow, Tylka, and Augustus-Horvath (2010) conducted interviews with women who identified as having positive body image. One of the overarching themes among these women was the appreciation of body functionality and engagement in behaviours to keep their bodies functioning well (e.g., by participating in sports or by eating healthy meals). In a similar vein, Frisén and Holmqvist (2010) interviewed early adolescent boys and girls with the aim of identifying common positive body image characteristics. Like the women interviewed by Wood-Barcalow et al., these adolescents' positive body image was characterised by a predominant focus on the functionality of the body rather than on the appearance of the body. These students valued their bodies' capability to perform in sports (e.g., "I can run really fast!") or in school activities (e.g., studying for an exam). In addition, most participants viewed physical activity as important in taking care of their bodies and in improving what their bodies can do. Frisén and Holmqvist advised parents and teachers to underline the importance of evaluating the body for its functionality, rather than for its appearance.

Further evidence for the benefits of focusing on body functionality comes from research on physical activity and yoga- based fitness. According to Martin and Lichtenberger (2002), engaging in physical activity may encourage people to focus more on the functionality of their bodies and to focus less on their appearance. They also stated that, unlike appearance, there are no strict cultural standards regarding body functionality to which people can compare. In a meta-analysis of physical activity interventions, Campbell and Hausenblas (2009) found that the interventions had a small positive effect on body satisfaction. Moreover, although greater exercise frequency produced larger improvements in body satisfaction, these improvements were unrelated to objective changes in physical fitness. These results paralleled previous findings (Fox, 2000; Martin \& Lichtenberger, 2002) and support the notion that exercise interventions may effectively improve body image by encouraging people to focus more on their body functionality. However, Campbell and Hausenblas noted that the underlying mechanisms must be better understood, because it could also be that physical activity produces subtle changes in appearance from which people may derive body satisfaction (Martin \& Lichtenberger, 2002).

Regarding yoga-based fitness specifically, it has been theorised that yoga teaches people to focus on how the body feels internally rather than on how the body looks (Boudette, 2006). For instance, exercises in yoga classes are based on observing internal sensations rather than on monitoring appearance, and mirrors are usually absent. Thus, by learning to focus on body functionality "on the mat," participants may adopt this focus outside yoga classes as well (Boudette, 2006). In support of this notion, Prichard and Tiggemann (2008) found that participation in yoga-based fitness classes was related to lower levels of self-objectification and to exercising for health and fitness reasons (which may reflect a functionality-based focus). Likewise, Daubenmier (2005) found that women who attended yoga-based fitness classes showed lower levels of self-objectification compared to women who participated in aerobics classes and to women who did not exercise. Notably, they also experienced greater levels of body satisfaction.

Finally, a massage intervention conducted by Dunigan, King, and Morse (2010) may provide more insight into the benefits of focusing on body functionality. In their study, the effect of massage on body image was investigated, wherein participants in the experimental group received a 50 -minute massage from a massage therapist, and participants in the control group watched a neutral documentary. The results showed that participants who received a massage experienced increased body satisfaction compared to the control participants. Dunigan et al. suggested that one of the reasons massage may improve body image is because it offers participants the opportunity to experience their bodies as a "vehicle for the experience of pleasure" (p. 411), where the focus is on how the body feels rather than on how the body looks.

These studies investigated body functionality in different ways and in different contexts, including mediational models, 
in-depth interviews, (yoga-based) fitness, and massage. The extant evidence for the benefits of focusing on body functionality is piecemeal yet promising. At the same time, the scarcity of this research highlights the importance of further investigation into body functionality.

\section{The Current Studies}

A handful of body image interventions has included elements related to body functionality as a component of their programs, for example, by encouraging participants to engage in behaviours that induce a feeling of mastery or pleasure rather than focusing on appearance (Butters \& Cash, 1987; Fisher \& Thompson, 1994; McLean, Paxton, \& Wertheim, 2011). Moreover, some eating disorder prevention programs have also challenged participants to describe their bodies in nonappearance terms, such as by commenting on their behavioural, emotional, or social characteristics while standing in front of a full-length mirror (Becker, Ciao, \& Smith, 2008; Stice, Trost, \& Chase, 2002). Although all of these programs have evidenced successful reductions in body dissatisfaction, it is important to note that the techniques related to body functionality that were included in these interventions were only a small part of a broader program.

Cash and Pruzinsky (2002b) stated that the lack of research into body functionality is one of the major limitations to research in body image and how to improve it. To the authors' knowledge, currently no body image interventions have focused exclusively on body functionality. In addition, the evidence for the body functionality approach discussed earlier is yet to be supported by experimental studies that have manipulated a functionality focus on the body. An experiment of this sort is necessary to determine causality and to directly evaluate the impact of focusing on body functionality. Therefore, by experimentally inducing a focus on body functionality in the current studies, we aimed to investigate emphasising body functionality as a method to improve body satisfaction. To this effect, we employed a randomised control design across two samples (an undergraduate sample of men and women and a community sample of 30 to 50 yearold women) with a pretest, posttest, and 1-week follow-up assessment.

We formulated the following hypotheses. First, we predict that focusing on the functionality of the body will improve body satisfaction, because previous research has suggested that a functionality-based approach to the body is related to positive body image. Second, in contrast, we expect that focusing on the appearance of the body will lead to a decrease in body satisfaction because an appearance-based focus on the body is an expression of self-objectification and has been related to negative body image. Third, we hypothesize that improvements in body image will persist at the 1-week follow-up, because a recent review of stand-alone body image interventions showed that body image gains persist over time (Jarry \& Berardi, 2004). Finally, we assessed global self-esteem because studies of body image interventions have shown that changes in body satisfaction are often paralleled by changes in self-esteem (Martijn, Vanderlinden, Roefs, Huijding, \& Jansen, 2010), which may be explained by the importance of appearance to women's self-esteem (Fredrickson \& Roberts, 1997; Lerner, Orlos, \& Knapp, 1976; Rodin et al., 1984). We therefore predict that focusing on body functionality will lead to an increase in global self-esteem, whereas focusing on body appearance will lead to a decrease in global self-esteem (given the negative effects of an appearance-based focus on body image).

\section{Study I}

In Study 1, we tested our hypotheses in a sample of undergraduate women and men. We decided to include men because, although women are more body dissatisfied than men are (Muth \& Cash, 1997), nearly half of all men are dissatisfied with their bodies as well (Garner, 1997). Body dissatisfaction in men has been shown to have many of the same negative consequences it has in women, such as low self-esteem, depression, and eating disorders, in addition to steroid use, muscle dysmorphia, and preoccupation with muscularity (Cafri, Olivardia, \& Thompson, 2008; Olivardia, Pope, Borowiecki, \& Cohane, 2004). Regarding objectification theory, research suggests that women are the primary targets of sexual objectification, not men (see Fredrickson \& Roberts, 1997, for a review) and that women show higher levels of trait self-objectification than men do (Fredrickson, Roberts, Noll, Quinn, \& Twenge, 1998). Moreover, in an experimental study where female and male participants tried on either a swimsuit (to induce self-objectification) or a sweater (control), men who tried on a swimsuit neither experienced body shame nor demonstrated restrained eating (Fredrickson et al., 1998). These results were replicated by Quinn et al. (2006), with the additional finding that there were no differences in the amount of body-related thoughts between men who tried on a swimsuit and men who tried on a sweater. These findings suggest that, although many men may be dissatisfied with their bodies, focusing on the appearance of their bodies does not immediately elicit body dissatisfaction.

With regard to focusing on the functionality of the body, men may be especially well suited to this approach. From a young age, differences in the ways that girls and boys view their bodies emerge. Stephens, Hill, and Hanson (1994) noted that girls view their bodies as objects to attract others, whereas boys view their bodies as instruments to achieve mastery over their environments. This contrast emerges largely due to differences in how girls and boys are socialised, such as through the toys they are given with which to play (e.g., Barbie vs. Ninja Turtle), the clothes in which they are dressed (e.g., dress vs. overalls), and the compliments given to them (e.g., "You look so pretty!" vs. "You're so strong!"; Franzoi, 1995; Stephens, Hill, \& Hanson, 1994). 
Similar to differences between girls and boys, women are more likely to focus on and judge their bodies for their beauty, but men are more likely to focus on and judge their bodies for their functionality (Cash \& Brown, 1989; Lerner et al., 1976). Moreover, women's self-concept is more affected by their perception of physical attractiveness, whereas men's self-concept is more affected by their perception of physical effectiveness (Lerner et al., 1976). These findings suggest that men's body orientation may be more functionality based than women's and that body functionality is important to men.

In light of this information, we specified our hypotheses for Study 1 to incorporate expectations based on the sex of the participants. We hypothesised that (a) focusing on the functionality of the body would improve body satisfaction both in women and in men, (b) focusing on the appearance of the body would lead to a decrease in body satisfaction in women but not in men, and (c) improvements in body image would persist at 1-week follow-up. As for self-esteem, we predicted that focusing on body functionality would improve global self-esteem both in women and in men. However, we predicted that focusing on body appearance would only lead to a decrease in self-esteem in women (because the appearance manipulation should not negatively affect men's body satisfaction).

\section{Method}

\section{Participants}

Fifty-nine female $\left(M_{\mathrm{age}}=20.31\right.$, standard deviation $[S D]=$ $2.10)$ and 59 male $\left(M_{\text {age }}=21.36, S D=2.02\right)$ participants completed baseline and test-day measures. The nationality of most participants was Dutch $(n=63,53.8 \%)$ followed by German ( $n=31,26.1 \%$ ), Eastern-European (e.g., Czech, Polish, Slovakian; $n=4$ ), and Northern European (e.g., Finnish, Swedish; $n=4)$. The nationalities of the remaining participants were American $(n=3)$, French $(n=3)$, South American (e.g., Brazilian, Chilean; $n=3$ ), Southern European (e.g., Portuguese, Spanish; $n=3$ ), Asian (e.g., Chinese; $n=2$ ), and Belgian $(n=2)$. Two female and six male participants did not complete the follow-up measures, leaving a total of 57 female $\left(M_{\text {age }}=20.23, S D=2.08\right)$ and 53 male $\left(M_{\text {age }}=21.52, S D=\right.$ 2.06) participants. Power analyses using $\mathrm{G}^{*}$ Power (Faul, Erdfelder, Lang, \& Buchner, 2007) indicated that the present sample size $(N=118)$ can detect significant small to medium differences $(f=.18)$ between the groups with a minimum statistical power of .84 and $\alpha=.05$.

\section{Procedure}

Participants $(N=125)$ were recruited from the undergraduate psychology program or by advertisements on campus for a study about "life satisfaction." After providing informed consent and using a randomisation program (Graph Pad Software, 2012), participants were randomly assigned into one of the three Body Approach conditions, functionality, appearance, or control. Participants who completed at least baseline and test-day measures were included in our analyses.

The study was completed from the participants' homes via an online experiment system. Each participant received a personalised link to the study that was e-mailed 2 days before the measures were to be completed. Reminder e-mails were sent until the participants completed the measures. At baseline, participants completed measures of body concern, body satisfaction, and global self-esteem. At test-day (1 week later), participants first completed the writing assignment and then measures of body satisfaction, global self-esteem, mood, and demographic information. At follow-up (1 week later), participants filled in measures of body satisfaction and global selfesteem. They were also asked to guess the purpose of the study (note that no participant guessed the purpose of the study). At the end of data collection, participants in the appearance condition received the functionality writing assignment to counteract any negative effects of the appearance writing assignment. Participants were debriefed at the end of the experiment and were compensated with 10 Euro and a chance to win an iPod.

\section{Experimental Manipulation}

To manipulate the body focus, a writing assignment was used, the structure of which was inspired by Pennebaker (1997). Participants in the functionality condition received the following instructions:

This is a writing assignment. I would like you to describe what your body can do. In your writing, I would like you to take your time, really let go and explore the different things your body can do. For example, you might want to tie your answer to physical activity and movement (e.g., walking, stretching), to health (e.g., healing, digesting), to daily functions (e.g., eating, sleeping), or even to your body's relationship with other people (e.g., hugging, holding hands). Different bodies can do many different things, so there are no right or wrong answers. Your answer will be unique depending on your body. All of your answers will be completely confidential and anonymous. Don't worry about spelling, sentence structure, or grammar. The only rule is that you write at least 100 words. (total word count of these instructions: 133)

Paralleling this same general structure, participants in the appearance condition received these instructions:

This is a writing assignment. I would like you to describe what your body looks like. In your writing, I would like you to take your time, really let go and explore the appearance of your body. For example, you might want to tie your answer to body shape and weight (e.g., height, bone structure), to facial features (e.g., eye brows, hair texture), to body parts (e.g., arms, hands), or even to your body's other markings (e.g., birthmarks, piercings). Different bodies ... [continuing as above]. (total word count: 129) 
Finally, the control participants received the following directions:

This is a writing assignment. I would like you to describe what your route to university is like. In your writing, I would like you to take your time, really let go and explore what your route is like. For example, you might want to tie your answer to signs (e.g., street signs, shop signs), to buildings (e.g., garages, libraries), to public areas (e.g., parks, market squares), or even to fine details (e.g., flowers, colours). Everyone takes a different route to the university, so there are no right or wrong answers. Your answer will be unique depending on the route you take. All of your answers ... [continuing as above]. (total word count: 131)

\section{Measures}

Body Concern was measured to check for group differences at baseline using the 36-item Eating Disorder ExaminationQuestionnaire (EDE-Q; Fairburn \& Beglin, 1994). The EDE-Q measures eating disorder pathology over the past 28 days and contains four subscales: Restraint, Eating Concern, Shape Concern, and Weight Concern. Answers are gathered on 7-point Likert-type scales ranging from 0 (not at all) to 6 (highly frequent). Participants completed all 36 items, but we only used items from the Shape Concern subscale ( 8 items; e.g., "On how many of the past 28 days have you had a definite desire to have a totally flat stomach?") and the Weight Concern subscale (5 items; e.g., "On how many of the past 28 days have you had a strong desire to lose weight?"). The two subscale items were averaged to create a single body concern score, with higher scores representing greater body concern (most of these items load onto one underlying factor; Peterson et al., 2007). In a sample of undergraduate women, the EDE-Q demonstrated good-toexcellent internal consistency ( $\alpha$ s of the subscales ranged from .81 to .93 ) and 2-week test-retest reliability ( $r s$ ranging from .81 to .94; Luce \& Crowther, 1999). In a community sample of women, EDE-Q scores were correlated with scores on the Eating Disorder Examination (EDE) interview ( $r$ of the subscales ranged from .68 to .78; Mond, Hay, Rodgers, Owen, \& Beaumont, 2004).

Body satisfaction was divided into appearance satisfaction and functionality satisfaction. Appearance satisfaction was measured using the 6-item Body Image States Scale (BISS; Cash, Fleming, Alindogan, Steadman, \& Whitehead, 2002) which taps the following dimensions based on how the participant feels "right now, at this very moment": (a) dissatisfaction-satisfaction with physical appearance, (b) dissatisfaction-satisfaction with body size and shape, (c) dissatisfaction-satisfaction with weight, (d) feelings of physical attractiveness-unattractiveness, (e) feelings about how one looks compared to how one usually feels, and (f) evaluation of appearance in comparison to the appearance of others. Participants rated their responses on $100 \mathrm{~mm}$ visual analogue scales (VAS). The ratings were averaged to create an appearance satisfaction score, with possible scores between 0 and 100, and with higher scores reflecting greater appearance satisfaction. In a sample of female and male undergraduates, the BISS demonstrated acceptable internal consistency as well as 2- to 3-week test-retest reliability of .68 (women) and 69 (men); BISS scores were also highly correlated with scores on other measures of body image (e.g., objectified body consciousness) and were sensitive to positive and negative contexts (Cash et al., 2002).

Functionality satisfaction was measured using an adapted version of The Visual Analogue Body Dissatisfaction Scale (VABDS; Heinberg \& Thompson, 1995). The VABDS is sensitive to changes in body satisfaction and correlates highly with other measures of body satisfaction (e.g., with the Body Dissatisfaction subscale of the Eating Disorder Inventory; Garner, 1991; Heinberg \& Thompson, 1995). In our study, participants were asked to rate how they feel "right now" regarding the statement "Overall, I am satisfied with everything that my body can do." The participants put a mark on a $100 \mathrm{~mm}$ horizontal line, with answer possibilities ranging from 0 (not at all) to 100 (very much).

Global self-esteem was assessed using the 10-item Rosenberg Self-Esteem Scale (RSES; Rosenberg, 1965). RSES items (e.g., "On the whole I am satisfied with myself") are rated on a 4-point Likert-type scale, ranging from 1 (strongly agree) to 4 (strongly disagree). After recoding the reversescored items, item ratings were summed, with higher scores indicating greater self-esteem. In a sample of undergraduate women and men, RSES scores were shown to be stable across measurement points (mean $r=.69$; Robins, Hendin, \& Trzesniewski, 2001); mean Cronbach's $\alpha$ across samples from over 50 countries including undergraduates and participants from the general population was .81 (Schmitt \& Allik, 2005). Across most of these countries, RSES scores were correlated positively with extroversion and negatively with neuroticism (Schmitt \& Allik, 2005).

Mood was measured to test for differences in mood at testday. Participants were asked to rate how they feel "right now" regarding the feelings anxious (reverse-scored), happy, sad (reverse-scored), positive, and energetic on $100 \mathrm{~mm}$ VASs, ranging from 0 (not at all) to 100 (very much). An average of the ratings was taken for a mood score $(\alpha=.78)$, with a higher score representing a more positive mood.

Demographic information included participants' age, sex, nationality, height, and weight. Self-reported weight and height were used to calculate body mass index (BMI, $\mathrm{kg} / \mathrm{m}^{2}$ ) to check for any differences in BMI between the conditions at baseline. To disguise the purpose of the study, all questionnaires were interspersed with filler questions (e.g., "Overall, I think that the availability of public transport in Maastricht is excellent"; "Overall, I think that the availability of housing options in Maastricht is excellent").

As a manipulation check, the writing assignment responses were scored for valence (i.e., how positively or negatively the participants described their bodies in the writing assignment), because we expected that describing body functionality would induce a more positive stance toward the 
Table I. Undergraduate's Mean Body Satisfaction and Self-Esteem Scores in the Three Body Approach Conditions Over Time.

\begin{tabular}{|c|c|c|c|c|c|c|c|c|c|}
\hline \multirow[b]{2}{*}{ Time Point } & \multicolumn{3}{|c|}{ Functionality Condition } & \multicolumn{3}{|c|}{ Appearance Condition } & \multicolumn{3}{|c|}{ Control Condition } \\
\hline & $\begin{array}{c}\text { Funct Satisf } \\
(M, S D)\end{array}$ & $\begin{array}{c}\text { Appear Satisf } \\
(M, S D)\end{array}$ & $\begin{array}{l}\text { Self-Esteem } \\
\quad(M, S D)\end{array}$ & $\begin{array}{l}\text { Funct Satisf } \\
(M, S D)\end{array}$ & $\begin{array}{c}\text { Appear Satisf } \\
(M, S D)\end{array}$ & $\begin{array}{l}\text { Self-Esteem } \\
\quad(M, S D)\end{array}$ & $\begin{array}{c}\text { Funct Satisf } \\
(M, S D)\end{array}$ & $\begin{array}{l}\text { Appear Satisf } \\
(M, S D)\end{array}$ & $\begin{array}{l}\text { Self-Esteem } \\
\qquad(M, S D)\end{array}$ \\
\hline \multicolumn{10}{|l|}{ Women } \\
\hline Baseline & $\begin{array}{c}68.44 \\
(19.65)\end{array}$ & $\begin{array}{c}52.18 \\
(13.46)\end{array}$ & $\begin{array}{l}29.56 \\
(4.90)\end{array}$ & $\begin{array}{c}67.86 \\
(22.26)\end{array}$ & $\begin{array}{c}54.51 \\
(19.93)\end{array}$ & $\begin{array}{l}29.00 \\
(5.19)\end{array}$ & $\begin{array}{c}64.95 \\
(19.86)\end{array}$ & $\begin{array}{c}55.24 \\
(11.92)\end{array}$ & $\begin{array}{l}30.25 \\
(5.07)\end{array}$ \\
\hline Testing & $\begin{array}{c}62.28 \\
(19.74)\end{array}$ & $\begin{array}{c}54.73 \\
(14.4 I)\end{array}$ & $\begin{array}{l}29.39 \\
(4.67)\end{array}$ & $\begin{array}{c}56.38 \\
(23.74)^{*}\end{array}$ & $\begin{array}{c}53.36 \\
(18.70)\end{array}$ & $\begin{array}{l}28.38 \\
(4.65)\end{array}$ & $\begin{array}{c}69.35 \\
(14.54)\end{array}$ & $\begin{array}{c}58.37 \\
(11.60)\end{array}$ & $\begin{array}{l}29.30 \\
(4.89)\end{array}$ \\
\hline Follow-up & $\begin{array}{c}63.24 \\
(17.56)\end{array}$ & $\begin{array}{c}54.34 \\
(14.31)\end{array}$ & $\begin{array}{l}29.65 \\
(4.97)\end{array}$ & $\begin{array}{c}57.52 \\
(25.05)^{*}\end{array}$ & $\begin{array}{c}55.08 \\
(18.18)\end{array}$ & $\begin{array}{l}29.43 \\
(5.17)\end{array}$ & $\begin{array}{r}72.68 \\
(11.47)\end{array}$ & $\begin{array}{c}56.44 \\
(10.18)\end{array}$ & $\begin{array}{l}29.21 \\
(4.59)\end{array}$ \\
\hline \multicolumn{10}{|l|}{ Men } \\
\hline Baseline & $\begin{array}{c}66.11 \\
(20.68)\end{array}$ & $\begin{array}{c}59.29 \\
(11.05)\end{array}$ & $\begin{array}{l}30.63 \\
(5.30)\end{array}$ & $\begin{array}{c}67.37 \\
(22.11)\end{array}$ & $\begin{array}{c}54.74 \\
(15.13)\end{array}$ & $\begin{array}{l}29.68 \\
(4.64)\end{array}$ & $\begin{array}{c}73.09 \\
(18.21)\end{array}$ & $\begin{array}{r}61.59 \\
(11.43)\end{array}$ & $\begin{array}{l}31.44 \\
(4.47)\end{array}$ \\
\hline Testing & $\begin{array}{l}78.32 \\
(12.11)^{*}\end{array}$ & $\begin{array}{c}61.57 \\
(14.74)\end{array}$ & $\begin{array}{l}31.37 \\
(4.80)\end{array}$ & $\begin{array}{c}58.42 \\
(25.99)\end{array}$ & $\begin{array}{c}53.69 \\
(18.67)\end{array}$ & $\begin{array}{l}29.84 \\
(5.33)\end{array}$ & $\begin{array}{c}70.30 \\
(13.60)\end{array}$ & $\begin{array}{c}61.74 \\
(13.20)\end{array}$ & $\begin{array}{l}31.52 \\
(4.21)\end{array}$ \\
\hline Follow-up & $\begin{array}{c}69.39 \\
(17.66)\end{array}$ & $\begin{array}{c}66.16 \\
(12.79)\end{array}$ & $\begin{array}{l}30.94 \\
(4.84)\end{array}$ & $\begin{array}{c}63.94 \\
(23.90)\end{array}$ & $\begin{array}{l}55.20 \\
(20.36)\end{array}$ & $\begin{array}{l}30.94 \\
(5.60)\end{array}$ & $\begin{array}{c}68.10 \\
(17.23)\end{array}$ & $\begin{array}{c}61.93 \\
(15.34)\end{array}$ & $\begin{array}{l}31.86 \\
(4.56)\end{array}$ \\
\hline
\end{tabular}

Note. Funct Satisf $=$ Functionality Satisfaction; Appear Satisf = Appearance Satisfaction; SD = standard deviation. Significant differences are always in reference to scores at baseline in the corresponding condition. $* p<.05$.

body than describing appearance. Valence was scored using a 5 -point scale from 1 (very negative) through 3 (neutral) to 5 (very positive). The control writing assignment was not scored, because it was unrelated to the body (the responses were checked to make sure that none mentioned the body). Two independent raters (one female and one male, for whom the condition, sex of respondent, and hypotheses were masked) were trained by the first author regarding what constituted each score. The raters then scored every appearance and functionality writing assignment response separately. Valence ratings that differed by at least two points (four cases) were discussed to reach consensus (i.e., a new score was decided upon). To compute the valence score, an average was taken of both the raters' scores. The interrater reliability between the raters was high; the intraclass coefficient was .80 . Finally, the word count of each writing assignment response was tallied to check for differences among conditions.

\section{Results}

\section{Participant Characteristics}

Thirty-seven participants (19 male, 18 female) composed the functionality condition, and 39 participants (18 male, 21 female) composed the appearance condition. The remaining 42 participants ( 22 male, 20 female) took part in the control condition. Female participants' BMI ranged from 17.99 to $31.19(M=21.97, S D=2.58)$; male participants' from 15.50 to $35.14(M=22.91, S D=3.43)$. There were no group differences at baseline in BMI, body concern, appearance and functionality satisfaction, or self-esteem scores, all $F \mathrm{~s}<1$.
There were no group differences in mood at test-day, $F(2$, $115)=1.22, p=.30$. The means and $S D$ s for all comparisons are reported in Table 1, and the correlations among the questionnaire scores at baseline are given in Table 2 . The results reported here did not change when the analyses were run with mood, BMI, and body concern as covariates. Also, no outliers (i.e., scores $3 S D$ above or below the group mean) were identified.

\section{Manipulation Checks}

Men's valence scores on the writing assignment were: functionality condition, $M=3.53, S D=0.61$, and appearance condition, $M=3.03, S D=0.54$. Women's valence scores on the writing assignment were: functionality condition, $M=3.31, S D=0.69$, and appearance condition, $M=$ $2.75, S D=0.79$. Results of an analysis of variance (ANOVA) of Body Approach and Sex on valence showed that only the main effect of Body Approach was significant, $F(1,70)=$ $11.42, p=.001$. Overall, responses to the writing assignments were more positive in the functionality condition, $M=3.42, S D=0.65$, compared to those in the appearance condition, $M=2.88, S D=0.69$.

Men's word count on the writing assignments was: functionality condition, $M=154.00, S D=115.97$; appearance condition, $M=160.00, S D=71.91$; and control condition, $M=184.26, S D=83.37$. Women's word count on the writing assignments was: functionality condition, $M=167.78$, $S D=77.00$; appearance condition, $M=156.90, S D=$ 92.87; and control condition, $M=264.42, S D=138.62$. An ANOVA of Body Approach and Sex on word count showed no significant effects. 
Table 2. Correlations Among the Measures of Study I and Study 2 at Baseline.

\begin{tabular}{lccc}
\hline Measures & FS & BISS & RSES \\
\hline Functionality satisfaction (FS) & - & $.42^{* *}$ & $.4 I^{* *}$ \\
Appearance satisfaction (BISS) & $.53^{* *}$ & - & $.52^{* *}$ \\
Global self-esteem (RSES) & $.43^{* *}$ & $.46^{* *}$ & $-.27^{* *}$ \\
Body concern (EDE-Q items) & $-.57^{* *}$ & $-.79^{* *}$ & $-.52^{* *}$ \\
\hline
\end{tabular}

Note. BISS = Body Image State Scale; RSES = Rosenberg Self-Esteem Scale; EDE-Q = Eating Disorders Examination-Questionnaire (Shape and Weight Concern subscales). Correlations for Study I appear above the diagonal, and correlations for Study 2 appear below the diagonal. $*^{* *} p<.01$.

\section{Functionality Satisfaction}

Participants' functionality satisfaction scores were analysed in a 2 between (Sex: female, male) $\times 3$ between (Body Approach: functionality, appearance, control) $\times 3$ within (Time: baseline, test-day, follow-up) repeated measures ANOVA. The result of Mauchly's test indicated a violation of the sphericity assumption, $\chi^{2}(2)=.936, p=.03$, so Greenhouse-Geisser corrections were applied. The main effects of Sex, Body Approach, and Time were nonsignificant, $F_{\mathrm{s}}<1$. The interaction between Sex and Time was nonsignificant, $F(1.88,195.45)=.28, p=.74$. Similarly, the interaction between Body Approach and Time was nonsignificant, $F(3.76,195.45)=2.42, p=.054$. However, the three-way interaction of Sex, Body Approach, and Time was significant, $F(3.76,195.45)=3.42, p=.01, \eta^{2}=.06$. (The following guidelines apply for interpreting eta-squared effect sizes: small $=0.01$, medium $=0.06$, and large $=0.14$; Cohen, 1988).

This analysis was followed up with separate repeated measures ANOVAs for men and women. The sphericity assumption was not violated for these analyses, so no corrections were applied. For men, the main effect of Time was nonsignificant, $F(2,100)=.14, p=.87$, whereas the interaction between Body Approach and Time was significant, $F(4$, $100)=2.96, p=.02, \eta^{2}=.11$. Similarly, for women, the main effect of Time was nonsignificant, $F(2,108)=1.08, p=.34$, whereas the interaction between Body Approach and Time was significant, $F(4,108)=2.85, p=.03, \eta^{2}=.09$.

Subsequently, we followed these interactions with planned contrasts based on our hypotheses; we compared the different time points (baseline with test-day, and baseline with followup) per Sex, and per Body Approach condition. Compared to baseline, men's functionality satisfaction significantly increased after writing about what their bodies can do, $p=.03$, 95\% confidence interval (CI): $[-21.91,-1.20]$. However, at 1 -week follow-up, this difference was no longer significant, $p=.64,95 \% \mathrm{CI}$ : $[-13.32,8.32]$. Moreover, there were no significant changes at test-day or at follow-up in men in the appearance condition or in the control condition. Men's functionality satisfaction scores over time are presented in Figure 1a.

In contrast to men, women's functionality satisfaction did not change at test-day or at follow-up after writing about what

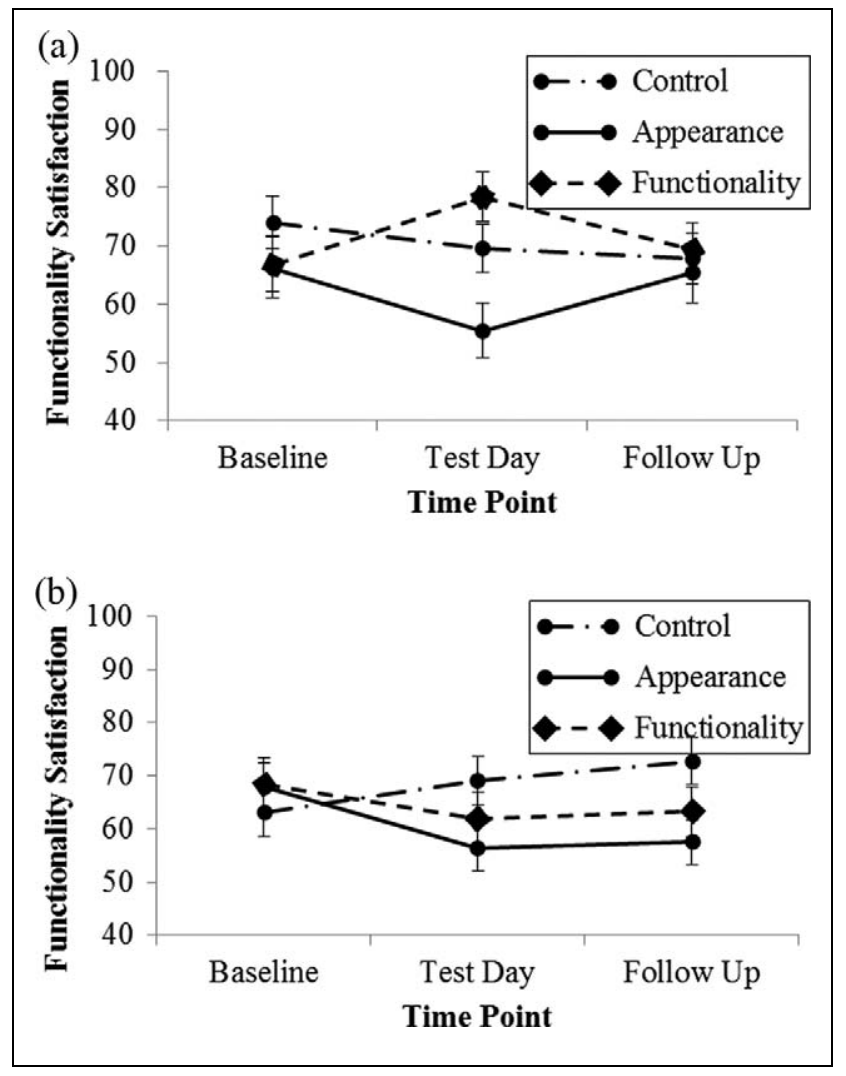

Figure I. Undergraduate (a) men's and (b) women's functionality satisfaction scores across time for the control, appearance, and functionality conditions.

their bodies can do. However, immediately after women wrote about their appearance, they showed decreased functionality satisfaction compared to baseline, $p=.02,95 \%$ CI $[1.86,21.06]$. Further, this difference was maintained at follow-up, $p=.04,95 \%$ CI $[0.51,20.16]$. Women in the control condition experienced no changes in functionality satisfaction at test-day or at follow-up. Women's functionality satisfaction scores over time are presented in Figure 1b.

\section{Appearance Satisfaction and Self-Esteem}

Participants' scores on appearance satisfaction were also analysed using a repeated measures ANOVA. The result of 
Mauchly's test of sphericity was nonsignificant, thus no corrections were applied. No main effects of Sex, Body Approach, or Time were found, $F \mathbf{s}<2.36$. The two-way interactions of Sex $\times$ Time and Body Approach $\times$ Time were both nonsignificant, $F \mathrm{~s}<1$. The three-way interaction of Sex $\times$ Body Approach $\times$ Time was also nonsignificant, $F<1$.

Regarding self-esteem, the result of Mauchly's test of sphericity was nonsignificant, so no corrections were needed. Results of a repeated measures ANOVA showed that the main effects of Sex, Body Approach, and Time were nonsignificant, $F \mathrm{~s}<3.47$. The two-way interactions of Sex $\times$ Time, and Body Approach $\times$ Time were both nonsignificant, $F \mathrm{~s}<1.84$. Finally, the three-way interaction of Sex, Body Approach, and Time was also nonsignificant, $F<1$.

\section{Discussion}

The aim of Study 1 was to establish whether focusing on body functionality would improve body satisfaction in a sample of undergraduate women and men. Our hypotheses were partially supported. First, in line with our first hypothesis, men in the functionality condition experienced an increase in one aspect of body satisfaction, namely, functionality satisfaction. Previous research has shown that people are more positive about their body functionality compared to their body appearance (Franzoi, 1995) and that men specifically are more inclined to think of their bodies in terms of functionality (Cash \& Brown, 1989; Franzoi, 1995; Stephens et al., 1994). In addition, men's self-concept is sculpted by their perception of their body functionality (Lerner et al., 1976). Thus, this "match" between men and the functionality-based focus on the body may have made the writing assignment both meaningful and effective for them.

Contrary to our first hypothesis, women in the functionality condition did not experience any change in their satisfaction with their body functionality or appearance. Research has shown that women are accustomed to thinking of their bodies in appearance terms rather than in functionality terms (e.g., Cash \& Brown, 1989; Franzoi, 1995; Fredrickson \& Roberts, 1997; Lerner et al., 1976; Stephens et al., 1994). Therefore, it is possible that the current writing assignment was too brief for these women to sufficiently focus and reflect on their body functionality. It may thus be necessary to have women complete the writing assignment more often and to require them to write longer responses to encourage more reflection on their body functionality.

Regarding our second hypothesis, as expected, women in the appearance condition experienced a decrease in functionality satisfaction. It is noteworthy that describing how their bodies look made women feel less satisfied with what their bodies can $d o$. Focusing on body appearance may have made the appearance dimension more salient, encouraging women to see their bodies as objects (Fredrickson \& Roberts, 1997; Fredrickson et al., 1998; Quinn, Kallen, \& Cathey, 2006). When seeing their bodies as objects, women may be less likely to perceive their body functionality positively (Roberts $\&$ Waters, 2004). It is also important to note that this decrease in functionality satisfaction even persisted at 1-week followup, which may reflect the overall, longer term negative impact of seeing the body as an object. One reason why women's appearance satisfaction did not decrease after writing about how their bodies look may be that appearance dissatisfaction has become normative to them (Rodin et al., 1984). Another reason may be that writing about the appearance of the body was not as confrontational as looking at the body in a mirror. Many studies have induced an appearance focus by having women stand in front of a mirror in a swimsuit, which has been shown to reduce body satisfaction (Moradi \& Huang, 2008). Finally, as expected, men in the appearance condition did not experience any changes in body satisfaction. This is in agreement with extant research that has demonstrated that men's body satisfaction is not immediately affected by focusing on the appearance of the body (Fredrickson et al., 1998; Quinn et al., 2006).

Finally, contrary to hypothesis, the positive changes in functionality satisfaction in men were not maintained at follow-up. The manipulation may not have been intense enough to instil longer lasting effects because writing 100 words did not consume much of the participants' time. Similarly, it is likely that global self-esteem, a rather stable construct, was not affected by the writing assignment given the short-term effects of the manipulation. Despite the absence of longer term positive changes in body satisfaction, or improvements in self-esteem, the current writing task did produce some of the expected effects at test-day, which is noteworthy considering its short duration and the ease with which it can be distributed.

\section{Study 2}

Our aim in Study 2 was to investigate whether focusing on body functionality would improve body satisfaction in a community sample of women between the ages of 30 and 50 years. Although most body image research has been conducted in women between 18 and 25 years old (Grogan, 1999), some studies have investigated body image in older women. Unfortunately, body dissatisfaction remains remarkably stable across the female life span (Grogan, 1999; Stevens \& Tiggemann, 1998; Tiggemann, 1992, 2004; Tiggemann \& Lynch, 2001). Considering that aging inevitably takes women's bodies further from the thin, youthful beauty ideal (Tiggemann, 2004), it is perhaps counterintuitive that body dissatisfaction does not increase with age.

However, there are reasons to suggest why body dissatisfaction in fact remains unaltered with time. For instance, a distinction can be made between the importance women place on their appearance and the evaluation of their appearance (i.e., body satisfaction; Muth \& Cash, 1997). Importance of appearance is reflected by how much women invest in their "looks" (e.g., via beauty rituals) and by how much appearance defines 
their sense of self (Muth \& Cash, 1997). In line with this notion, studies have shown that the importance of appearance decreases as women get older, even though body dissatisfaction remains stable (Pliner, Chaiken, \& Flett, 1990; Tiggemann \& Lynch, 2001). Furthermore, Webster and Tiggemann (2003) demonstrated that as women age, they adopt more cognitive strategies that help them cope with body changes, such as making reappraisals, lowering their expectations (e.g., regarding a realistic weight), or accepting physical aspects they cannot change (e.g., the appearance of wrinkles). It has also been hypothesised that, over time, women compare their bodies with more age-appropriate peers (Grogan, 1999), which has been supported by research, which demonstrates that women's ideal body shape becomes more realistic as they age and as their BMI increases (Stevens \& Tiggemann, 1998; Tiggemann \& Lynch, 2001).

Another explanation for the stability of body dissatisfaction across the female lifespan stems from objectification theory (Fredrickson \& Roberts, 1997). Objectification theory posits that women are most targeted for sexual objectification in the reproductive stage of their lives. Thus, self-objectification should intensify during adolescence and decline as women get older, allowing older women to "escape from the culture of objectification along with its negative psychological repercussions" (Fredrickson \& Roberts, 1997, p. 195) such as body shame and anxiety. Central to this shift is that older women should no longer hold the outside observer perspective on their bodies as the main view of themselves, thus they will likely place less importance on their appearance (Fredrickson \& Roberts, 1997; Tiggemann \& Lynch, 2001). The first known study to investigate the relation among self-objectification, body image, and age was conducted by Tiggemann and Lynch (2001) and has supported these postulations. In their crosssectional study, they showed that self-objectification decreases as women get older as do its corollaries body monitoring and appearance anxiety. (Note, however, that levels of body dissatisfaction and body shame remained stable.) The authors concluded that as women age, appearance is deemphasised (lower self-objectification), is critiqued less (reduced body monitoring), and evokes less anxiety (lower appearance anxiety).

Regarding body functionality, to the authors' knowledge, no studies have investigated satisfaction with body functionality over the lifespan so the notions we propose here are speculative. Similar to aspects of appearance, certain aspects of body functionality may decline as women age (Hurd, 2000). For example, as women get older, they may need to rely on functional aids (e.g., glasses) or may experience more frequent bodily pain compared to younger women. In addition, physical life changes, such as menopause, may pose a challenge to body image (Tiggemann, 2004). In this light, satisfaction with body functionality should decrease as women get older (Hurd, 2000).

On the other hand, mature women may have more positive body functionality experiences to draw from than younger women do, such as childbirth or raising a family. Also, many skills may become more refined and improved over time, which may elicit satisfaction with body functionality as well. Moreover, as discussed earlier, women focus less on their appearance as they get older (Fredrickson \& Roberts, 1997; Tiggemann \& Lynch, 2001). This may give women "room" to shift their focus to other dimensions of their bodies, namely, to the functionality dimension. These two factors may counteract negative changes in body functionality satisfaction that women may experience as they get older. For these reasons, and considering the benefits of focusing on body functionality (discussed in the general introduction), in Study 2 we hypothesised that focusing on body functionality would improve body satisfaction. Given that importance of appearance decreases with age, we hypothesised that describing body appearance would not lead to decreases in body satisfaction. We further hypothesised that changes in body satisfaction would persist at 1-week follow-up and that global self-esteem would improve in women who focus on body functionality. (We did not expect changes in global self-esteem in the appearance group.)

\section{Method}

\section{Participants and Procedure}

A total of 118 participants $(M$ age $=40.98, S D=5.84$, range $=30-50)$ completed baseline and test-day measures. Eight participants did not complete follow-up measures, leaving a total of 110 participants $(M$ age $=40.78, S D=5.75$, range $=30-50$ ). All participants were of Dutch nationality. Power analyses using $\mathrm{G}^{*}$ Power (Faul et al., 2007) indicated that the present sample size $(N=118)$ can detect significant small differences $(f=.10)$ between the groups with a minimum statistical power of .88 and $\alpha=.05$.

To recruit baseline participants $(N=125)$, a chain or snowball sampling method was used. An initial sample of five women between 30 and 50 years old each distributed an invitation to participate in the study to approximately 10 other women in this age group. These women, in turn, invited other eligible women to participate in the study. Note that the initial five women did not participate in the study themselves nor were they aware of the hypotheses. Participants who completed at least baseline and test-day measures were included in the analyses. The remainder of the procedure was identical to Study 1. Regarding the experimental manipulation, control participants described the route to the store or shopping centre where they do their shopping. All other instructions remained the same.

\section{Measures}

In Study 2, the original BISS (six 7-point Likert-type scales) was administered. All other measures remained the same: EDE-Q (Weight and Shape Concern items combined), RSES, and mood $(\alpha=.86)$. The ratings for valence scores differed by 2 points between the raters in four cases; these 
Table 3. Women's Mean Body Satisfaction and Self-Esteem Scores in the Three Body Approach Conditions Over Time.

\begin{tabular}{|c|c|c|c|c|c|c|c|c|c|}
\hline \multirow[b]{2}{*}{ Time Point } & \multicolumn{3}{|c|}{ Functionality Condition } & \multicolumn{3}{|c|}{ Appearance Condition } & \multicolumn{3}{|c|}{ Control Condition } \\
\hline & $\begin{array}{l}\text { Funct Satisf } \\
(M, S D)\end{array}$ & $\begin{array}{c}\text { Appear Satisf } \\
(M, S D)\end{array}$ & $\begin{array}{l}\text { Self-Esteem } \\
(M, S D)\end{array}$ & $\begin{array}{l}\text { Funct Satisf } \\
(M, S D)\end{array}$ & $\begin{array}{c}\text { Appear Satisf } \\
(M, S D)\end{array}$ & $\begin{array}{l}\text { Self-Esteem } \\
(M, S D)\end{array}$ & $\begin{array}{l}\text { Funct Satisf } \\
(M, S D)\end{array}$ & $\begin{array}{c}\text { Appear Satisf } \\
(M, S D)\end{array}$ & $\begin{array}{l}\text { Self-Esteem } \\
\quad(M, S D)\end{array}$ \\
\hline Baseline & $\begin{array}{c}77.00 \\
(21.47)\end{array}$ & $\begin{array}{l}4.60 \\
(1.01)\end{array}$ & $\begin{array}{l}32.60 \\
(4.89)\end{array}$ & $\begin{array}{c}77.62 \\
(21.89)\end{array}$ & $\begin{array}{c}4.31 \\
(1.09)\end{array}$ & $\begin{array}{l}34.03 \\
(4.95)\end{array}$ & $\begin{array}{c}74.05 \\
(21.67)\end{array}$ & $\begin{array}{l}4.69 \\
(1.01)\end{array}$ & $\begin{array}{l}33.13 \\
(5.55)\end{array}$ \\
\hline Testing & $\begin{array}{c}81.15 \\
(17.30)\end{array}$ & $\begin{array}{c}4.73 \\
(0.89)\end{array}$ & $\begin{array}{l}32.85 \\
(4.74)\end{array}$ & $\begin{array}{c}81.15 \\
(14.87)\end{array}$ & $\begin{array}{c}4.55 \\
(1.03)\end{array}$ & $\begin{array}{l}33.48 \\
(4.8 I)\end{array}$ & $\begin{array}{c}71.63 \\
(19.10)\end{array}$ & $\begin{array}{c}4.57 \\
(1.08)\end{array}$ & $\begin{array}{l}33.18 \\
(4.87)\end{array}$ \\
\hline Follow-up & $\begin{array}{l}80.17 \\
(15.54)^{*}\end{array}$ & $\begin{array}{c}4.57 \\
(0.93)\end{array}$ & $\begin{array}{l}32.86 \\
(5.74)\end{array}$ & $\begin{array}{l}76.35 \\
(21.61)\end{array}$ & $\begin{array}{c}4.51 \\
(1.06)\end{array}$ & $\begin{array}{l}33.43 \\
(4.4 I)\end{array}$ & $\begin{array}{l}74.06 \\
(21.12)\end{array}$ & $\begin{array}{c}4.71 \\
(1.14)\end{array}$ & $\begin{array}{l}33.39 \\
(5.12)\end{array}$ \\
\hline
\end{tabular}

Note. Funct Satisf = Functionality Satisfaction; Appear Satisf = Appearance Satisfaction; SD = standard deviation. The significant difference is in reference to the baseline score in the corresponding condition.

$*_{p}<.05$.

cases were discussed to reach consensus. Interrater reliability was high between the two raters; the intraclass correlation coefficient was .72 .

\section{Results \\ Participant Characteristics}

Forty-one participants composed the functionality condition, and 39 participants composed the appearance condition. The remaining 38 participants took part in the control condition. BMIs ranged between 18.10 and $43.36(M=24.04, S D=$ 3.99). There were no group differences at baseline in BMI, body concern, appearance and functionality satisfaction, or in self-esteem, $F \mathrm{~s}<1.10$. There were no group differences in mood at test-day, $F(2,115)=0.01, p=.99$. The correlations among the questionnaire scores at baseline are given in Table 2, and the means and $S D$ s for all comparisons are reported in Table 3. The results of the analyses reported below did not change when run with mood, BMI, and body concern as covariates. Regarding outliers (identified as a score $3 S D$ s above or below the group mean), only one was detected; the results did not change when this participant was excluded, so she was not removed from the data set.

\section{Manipulation Checks}

The valence scores for the writing assignment were: functionality condition, $M=3.39, S D=0.63$, and appearance condition, $M=2.99, S D=0.67$. Valence scores differed by Body Approach condition, $F(1,78)=7.68, p=.001, \eta^{2}=.09$. Participants described their bodies more positively in the functionality condition compared to the appearance condition. The word count on the writing assignments was: functionality condition, $M=156.59, S D=79.99$; appearance condition, $M=168.77, S D=69.42$; and control condition, $M=169.18$, $S D=78.38$. An ANOVA of Body Approach on word count showed no significant results, $F(2,115)=0.36, p=.70$.

\section{Functionality Satisfaction}

Women's functionality satisfaction scores were analysed in a 3 between (Body Approach: functionality, appearance, control) $\times 3$ within (Time: baseline, test-day, follow-up) repeated measures ANOVA. The result of Mauchly's test of sphericity revealed no violation of the sphericity assumption, so no corrections were applied. The main effects of Body Approach and Time were nonsignificant, $F \mathrm{~s}<1$. A significant interaction between Body Approach and Time was found, $F(4,206)=2.58, p=.04, \eta^{2}=.05$. Subsequently, we followed this interaction with planned contrasts based on our hypotheses, comparing levels of functionality satisfaction from baseline to test-day, and from baseline to follow-up, for each group separately. Although women in the functionality condition experienced improvements in functionality satisfaction from baseline to test-day (see Table 3), the results did not reach significance, $p=.12,95 \%$ CI $[-8.46,1.02]$. However, at follow-up, the improvements in functionality satisfaction in women in the functionality condition were significant, $p=.04,95 \%$ CI $[-9.25,-.31]$. No significant changes were found in women in the appearance condition or in the control conditions, both at test-day and at followup. Women's functionality satisfaction scores over time are presented in Figure 2.

\section{Appearance Satisfaction and Self-Esteem}

Participants' scores on appearance satisfaction were analysed using a repeated measures ANOVA. The result of Mauchly's test of sphericity showed a significant violation of the sphericity assumption, $\chi^{2}(2)=.93, p=.02$, so Greenhouse-Geisser corrections were applied. The results showed that the main effects of Body Approach and Time were nonsignificant, $F \mathrm{~s}<1$. Furthermore, the interaction between Body Approach and Time was also nonsignificant, $F<1.81$. Additionally, a repeated measures ANOVA was conducted to analyse participants' selfesteem scores. The sphericity assumption was not violated according to Mauchley's test, so no corrections were applied. The main effects of Body Approach and Time were both 


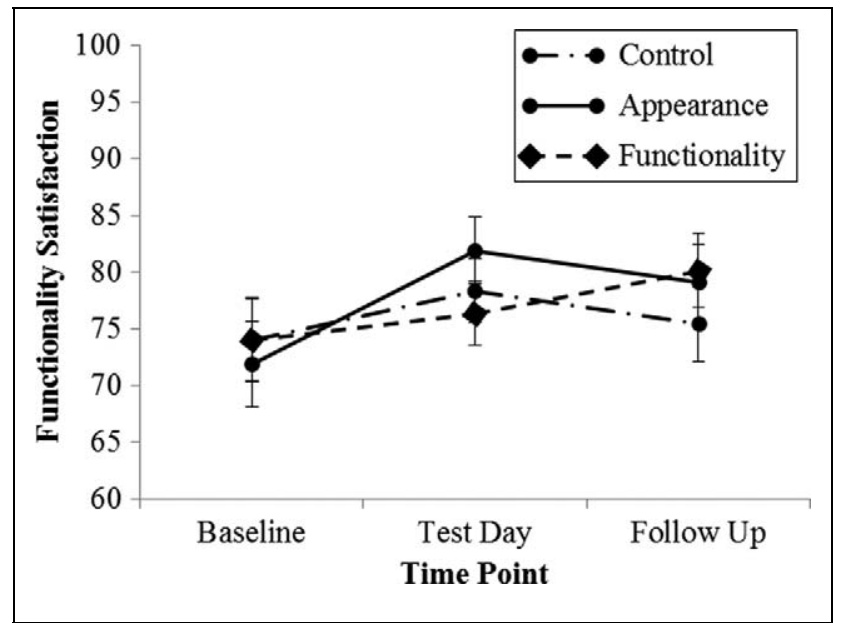

Figure 2. Women's functionality satisfaction scores across time for the control, appearance, and functionality conditions.

nonsignificant, $F \mathrm{~s}<1$. Additionally, the interaction between Body Approach and Time was nonsignificant, $F<1.67$.

\section{Discussion}

The aim of Study 2 was to establish whether focusing on body functionality would improve body satisfaction in a community sample of mature women. In Study 2, our hypotheses were partially supported. Although women who focused on their body functionality experienced improvements in functionality satisfaction at test-day, these improvements did not reach significance. Interestingly, these women did experience significant improvements in functionality satisfaction from baseline to follow-up. This finding implies that the improvements in functionality satisfaction were gradual yet longer lasting. It could be that these women reflected more on their bodies in functionality terms between test-day and follow-up. Moreover, similar to the men in Study 1, for mature women, body functionality may be a suitable "match" with their selfconcept that becomes less dependent on appearance over time (Fredrickson \& Roberts, 1997).

As expected, women who described their appearance did not experience any change in body satisfaction. This may also reflect an underlying decrease in the importance of appearance, whereby describing appearance does not negatively affect women's body image. Contrary to expectation, selfesteem did not improve in the functionality condition. Similar to Study 1, the brevity of the writing assignment may not have been strong enough to alter a stable construct such as global self-esteem. It is also likely that the writing task needs to be intensified to achieve stronger and longer lasting effects.

\section{General Discussion}

Body functionality constitutes the unobservable dimension of the body, which largely goes unnoticed in comparison to body appearance - the observable dimension of the body on which an inordinate amount of focus and importance is placed (Avalos \& Tylka, 2006; Franzoi, 1995; Franzoi \& Shields, 1984; Fredrickson \& Roberts, 1997; Wood-Barcalow, Tylka, \& Augustus-Horvath, 2010). Using objectification theory as a guiding framework, we have argued that focusing on body functionality (instead of body appearance) may improve body satisfaction. The current studies are the first known to experimentally manipulate a functionality-based approach to the body. Our hypotheses were partially supported. In Study 1, we found that undergraduate men (but not women) became more satisfied with everything their bodies can do when they focused on their body functionality. We also found that undergraduate women who focused on their body appearance felt less satisfied with what their bodies can do, both at test-day and at follow-up. In Study 2, we showed that mature women also became more satisfied with their body functionality when they described their bodies in functionality terms, but these changes were more gradual and only reached significance at 1 week follow-up. Unexpectedly, although undergraduate men and mature women experienced improvements in functionality satisfaction, they did not experience any improvements in appearance satisfaction. Therefore, the effects of the functionality writing assignment appear to be dimension-specific and did not extend to the appearance dimension of body image. Also unexpectedly, no improvements in global self-esteem were found.

Apart from discussing the findings of Study 1 and Study 2 separately, it is vital to draw some of the findings of both studies together. Fredrickson and Roberts (1997) posited that women are most targeted for sexual objectification in their reproductive years, whereas mature women gradually become free of this burden. We suggested that mature women would therefore focus more on the functionality of their bodies and that body functionality would be a source of greater satisfaction for them. Indeed, retrospectively, looking at functionality satisfaction at baseline between Study 1 women and Study 2 women, we do see that mature women $(M=76.25, S D=$ $21.54)$ are significantly more satisfied with their body functionality than the younger women $(M=68.05, S D=20.37)$ are, $t(175)=2.73, p=.01$. Furthermore, in Study 1, women who wrote about their appearance experienced both a short and longer term decrease in functionality satisfaction, whereas this was not the case in mature women. These findings suggest that, as appearance becomes less important in mature women (Muth $\&$ Cash, 1997), other aspects of their body (such as body functionality) become more important.

Another commonality between Study 1 and Study 2 is the absence of effects on appearance satisfaction. One reason for this absence may be the nature of the writing assignment instructions. The instructions for all writing assignments were purposely phrased in a neutral way to avoid biasing the participants' answers positively or negatively. In fact, responses to the appearance writing assignments received a neutral valence score in both the studies. Previous research has 
shown that having participants describing their bodies neutrally may diffuse negative feelings toward their appearance (Jansen et al., 2008). This may explain why women in the appearance condition did not experience changes in appearance satisfaction. This does not explain, however, why undergraduate men and mature women who focused on their body functionality did not experience an improvement in appearance satisfaction (despite experiencing improvements in functionality satisfaction). First, the relations between appearance satisfaction and functionality satisfaction are unclear; it could be that neither causes the other. Additionally, it is possible that describing body functionality does not change appearance satisfaction but rather the importance placed on appearance. In other words, reflecting on all the things the body can do may put appearance into perspective, without necessarily increasing satisfaction with appearance.

\section{Limitations and Future Directions}

Several limitations to the current studies should be mentioned. First, information about ethnicity, socioeconomic status, sexual orientation, and eating disorder history was not collected. These factors may have influenced participants' responses and should be incorporated into future studies. Second, although the online administration of the studies was convenient for participants, it was not possible to control for factors that may have influenced participants while writing. Third, several participants did not write the requested number of words for the writing assignment (8 participants in Study 1 wrote between 37 and 97 words; and 13 participants in Study 2, 16-92 words). In future experiments, participants should be required to fulfil the word count before continuing with the outcome measures so as to ensure that all participants reflect on the subject matter sufficiently. Fourth, the writing assignment did not instil any longer term improvements in body satisfaction in Study 1. As previously noted, to strengthen the effects of the writing assignment, it may be necessary to administer it repeatedly (e.g., several times per week), to intensify it (e.g., by increasing the required word count), and to alter the instructions (e.g., by framing the writing instructions positively rather than neutrally). Fifth, any comparisons made between Study 1 and Study 2 women are speculative. To directly compare between these groups of women, it will be important to conduct a study that includes women of various age groups within the same study. Finally, a major limitation of the current studies concerns the measurement of functionality satisfaction. Unfortunately, a validated questionnaire devoted entirely to body functionality does not currently exist. Therefore, we stress the importance of developing a measure of body functionality to drive and improve research in this field.

For future research, it will be important to incorporate these changes. In addition, it will be necessary to investigate how the functionality approach can be applied in younger women. It could be that an intensified manipulation is required, because younger women are accustomed to thinking of and evaluating their bodies in terms of appearance rather than functionality (Cash \& Brown, 1989; Fredrickson \& Roberts, 1997; Lerner et al., 1976). Furthermore, given the relevance of objectification theory for the functionalitybased approach, it will also be imperative to include measures of self-objectification as well as body shame and body monitoring. In this way, the proposed mechanisms of the functionality-based approach can be empirically tested and developed further.

\section{Conclusion}

In sum, the current studies contributed to the body image literature by experimentally manipulating a functionality-based focus on the body as a novel technique to improve body satisfaction. Two groups that are largely underrepresented in body image research were included, namely, undergraduate men and mature women. We provided preliminary support for focusing on the functionality of the body and have identified important limitations that should be addressed in future research on body functionality. Furthermore, we have also incorporated objectification theory, one of the most substantial theories regarding women's body image, into the field of body functionality research. We echo the statements of previous researchers who stressed the importance of focusing on the functionality of the body as a method of improving body image (Avalos \& Tylka, 2006; Frisén \& Holmqvist, 2010). It is hoped that the groundwork laid by our studies will only be the start of a burgeoning field into a neglected, yet potentially vital, aspect of body image.

\section{Declaration of Conflicting Interests}

The author(s) declared no potential conflicts of interest with respect to the research, authorship, and/or publication of this article.

\section{Funding}

The author(s) disclosed receipt of the following financial support for the research, authorship, and/or publication of this article: The contribution of Jessica M. Alleva was supported by NWO grant 404-10118: Novel strategies to enhance body satisfaction.

\section{References}

Avalos, L. C., \& Tylka, T. L. (2006). Exploring a model of intuitive eating with college women. Journal of Counseling Psychology, 53, 486-497. doi:10.1037/00220167.53.4.486

Avalos, L., Tylka, T. L., \& Wood-Barcalow, N. (2005). The body appreciation scale: Development and psychometric evaluation. Body Image, 2, 285-297. doi:10.1016/j.bodyim.2005.06.002

Bartky, S. L. (1990). Femininity and domination: Studies in the phenomenology of oppression. New York, NY: Routledge.

Becker, C. B., Ciao, A. C., \& Smith, L. M. (2008). Moving from efficacy to effectiveness in eating disorders prevention: The sorority body image program. Cognitive and Behavioral Practice, 15, 18-27. doi:1077-7229/07/018-027\$1.00/0 
Bernard, P., Gervais, S., Allen, J., Campomizzi, S., \& Klein, O. (2012). Integrating sexual objectification with object versus person recognition: The sexualized-body-inversion hypothesis. Psychological Science, 23, 469-471. doi:10.1177/0956797611434748

Boudette, R. (2006). Question \& answer: Yoga in the treatment of disordered eating and body image disturbance: How can the practice of yoga be helpful in recovery from an eating disorder? Eating Disorders, 14, 167-170. doi:10.1080/10640260500536334

Butters, J. W., \& Cash, T. F. (1987). Cognitive-behavioural treatment of women's body-image dissatisfaction. Journal of Consulting and Clinical Psychology, 55, 889-897.

Cafri, G., Olivardia, R., \& Thompson, J. (2008). Symptom characteristics and psychiatric comorbidity among males with muscle dysmorphia. Comprehensive Psychiatry, 49, 374-379. doi:10. 1016/j.comppsych.2008.01.003

Campbell, A., \& Hausenblas, H. A. (2009). Effects of exercise interventions on body image: A meta-analysis. Journal of Health Psychology, 14, 780-793. doi:10.1177/1359105309338977

Cash, T. F., \& Brown, T. A. (1989). Gender and body images: Stereotypes and realities. Sex Roles, 21, 361-373.

Cash, T. F., \& Fleming, E. C. (2002a). Body image and social relations. In T. F. Cash \& T. Pruzinsky (Eds.), Body image: A handbook of theory, research, and clinical practice (pp. 277-286). New York, NY: Guilford Press.

Cash, T. F., \& Fleming, E. C. (2002b). The impact of body-image experiences: Development of the Body Image Quality of Life Inventory. International Journal of Eating Disorders, 31, 455-460. doi:10.1002/eat.10033

Cash, T. F., Fleming, E. C., Alindogan, J., Steadman, L., \& Whitehead, A. (2002). Beyond body image as a trait: The development and validation of the Body Image States Scale. Eating Disorders: The Journal of Treatment and Prevention, 10, 101-113. doi:10. 1080/10640260290081678

Cash, T. F., \& Pruzinsky, T. (2002a). Body image: A handbook of theory, research, and clinical practice. New York, NY: Guilford Press.

Cash, T. F., \& Pruzinsky, T. (2002b). Future challenges for body image theory, research, and clinical practice. In T. F. Cash \& T. Pruzinsky (Eds.), Body image: A handbook of theory, research, and clinical practice (pp. 509-516). New York, NY: Guilford Press.

Cohen, J. (1988). Statistical power analysis for the behavioral sciences (2nd ed.). Hillsdale, NJ: Lawrence Erlbaum.

Cooley, E., \& Toray, T. (2001). Body image and personality predictors of eating disorder symptoms during the college years. International Journal of Eating Disorders, 30, 28-36. doi:10.1002/eat.1051

Daubenmier, J. J. (2005). The relationship of yoga, body awareness, and body responsiveness to self-objectification and disordered eating. Psychology of Women Quarterly, 29, 207-219. doi:10. 1111/j.1471-6402.2005.00183.x

Dunigan, B. J., King, T. K., \& Morse, B. J. (2010). A preliminary examination of the effect of massage on state body image. Body Image, 8, 411-414. doi:10.1016/j.bodyim.2011.06 .004

Fairburn, C. G., \& Beglin, S. J. (1994). The assessment of eating disorders: Interview or self report questionnaire? International Journal of Eating Disorders, 16, 363-370. doi:10.1002/1098108X(199412)16:4<363::AID-EAT2260160405>3.0.CO;2-\#
Faul, F., Erdfelder, E., Lang, A.-G., \& Buchner, A. (2007). G*Power 3: A flexible statistical power analysis for the social, behavioral, and biomedical sciences. Behavior Research Methods, 39, 175-191. doi:10.3758/BF03193146

Fisher, E., \& Thompson, J. K. (1994). A comparative evaluation of cognitive-behavioral therapy (CBT) versus exercise therapy (ET) for the treatment of body image disturbance: Preliminary findings. Behavior Modification, 18, 171-185. doi:10.1177/ 01454455940182002

Fox, K. R. (2000). The effects of exercise on self-perceptions and self-esteem. In S. J. H. Biddle, K. R. Fox, \& S. H. Boutcher (Eds.), Physical activity and psychological well-being (pp. 88-117). London, England: Routledge.

Franzoi, S. L. (1995). The body-as-object versus the body-asprocess: Gender differences and gender considerations. Sex Roles, 33, 417-437. doi:10.1007/BF01954577

Franzoi, S. L., \& Shields, S. A. (1984). The Body Esteem Scale: Multidimensional structure and sex differences in a college population. Journal of Personality Assessment, 48, 173-178.

Fredrickson, B. L., \& Roberts, T. A. (1997). Objectification theory: Toward understanding women's lived experiences and mental health risks. Psychology of Women Quarterly, 21, 173-206. doi:10.1111/j.1471-6402.1997.tb00108.x

Fredrickson, B. L., Roberts, T. A., Noll, S. M., Quinn, D. M., \& Twenge, J. M. (1998). That swimsuit becomes you: Sex differences in self-objectification, restrained eating, and math performance. Journal of Personality and Social Psychology, 75, 269-284.

Frisén, A., \& Holmqvist, K. (2010). What characterizes early adolescents with a positive body image? A qualitative investigation of Swedish girls and boys. Body Image, 7, 205-212. doi:10.1016/ j.bodyim.2010.04.001

Garner, D. M. (1991). Eating Disorder Inventory-2. Odessa, FL: Psychological Assessment Resources.

Garner, D. M. (1997). The 1997 body image survey results. Psychology Today, 30, 75-84.

Gervais, S. J., Vescio, T. K., Förster, J., Maass, A., \& Suitner, C. (2012). Seeing women as objects: The sexual body part recognition bias. European Journal of Social Psychology, 42, 743-753. doi:10.1002/ejsp. 1890

Graph Pad Software. (2012). Quick Calcs. Retrieved from http:// graphpad.com/quickcalcs/randomize1.cfm

Grogan, S. (1999). Body image. London, England: Routledge.

Halliwell, E., Malson, H., \& Tischner, I. (2011). Are contemporary media images which seem to display women as sexually empowered actually harmful to women? Psychology of Women Quarterly, 35, 38-45. doi:10.1177/0361684310385217

Haslam, N., Loughnan, S., \& Holland, E. (2013). The psychology of humanness. In S. J. Gervais (Ed.), Objectification and (De) humanization (pp. 25-51). New York, NY: Springer.

Heflick, N. A., \& Goldenberg, J. L. (2009). Objectifying Sarah Palin: Evidence that objectification causes women to be perceived as less competent and less fully human. Journal of Experimental Social Psychology, 45, 598-601. doi:10.1016/j.jesp.2009. 02.008 
Heflick, N. A., Goldenberg, J. L., Cooper, D. P., \& Puvia, E. (2011). From women to objects: Appearance focus, target gender, and perceptions of warmth, morality and competence. Journal of Experimental Social Psychology, 47, 572-581. doi:10.1016/j. jesp.2010.12.020

Heinberg, L. J., \& Thompson, J. K. (1995). Body image and televised images of thinness and attractiveness: A controlled laboratory investigation. Journal of Social and Clinical Psychology, 14, 325-338. doi:10.1521/jscp.1995.14.4.325

Hurd, L. C. (2000). Older women's body image and embodied experience: An exploration. Journal of Women and Aging, 12, 77-97. doi:10.1300/J074v12n03_06

Jansen, A., Bollen, D., Tuschen-Caffier, B., Roefs, A., Tanghe, A., $\&$ Braet, C. (2008). Mirror exposure reduces body dissatisfaction and anxiety in obese adolescents: A pilot study. Appetite, 51, 214-217. doi:10.1016/j.appet.2008.01.011

Jarry, J. L., \& Berardi, K. (2004). Characteristics and effectiveness of stand-alone body image treatments: A review of the empirical literature. Body Image, 1, 319-333. doi:10.1016/j.bodyim.2004.10.005

Kozee, H. B., Tylka, T. L., Augustus-Horvath, C. L., \& Denchik, A. (2007). Development and psychometric evaluation of the InterPersonal Sexual Objectification Scale. Psychology of Women Quarterly, 31, 176-189. doi:0361-6843/07

Lerner, R. M., Orlos, J. B., \& Knapp, J. R. (1976). Physical attractiveness, physical effectiveness and self-concept in late adolescents. Adolescence, 11, 313-326.

Loughnan, S., \& Haslam, N. (2007). Animals and androids: Implicit associations between social categories and nonhumans. Psychological Science, 18, 116-121. doi:10.1111/j.1467 9280.2007.01858.x

Luce, K. H., \& Crowther, J. H. (1999). The reliability of the Eating Disorder Examination Self-Report Questionnaire version (EDEQ). International Journal of Eating Disorders, 25, 349-351. doi: 10.1001/(SICI)1098-108X(199904)25:3<349::AID-EAT15> 3.0. $\mathrm{CO} ; 2-\mathrm{M}$

Martijn, C., Vanderlinden, M., Roefs, A., Huijding, J., \& Jansen, A. (2010). Increasing body satisfaction of body concerned women through evaluative conditioning using social stimuli. Health Psychology, 29, 514-520. doi:10.1037/a0020770

Martin, K. A., \& Lichtenberger, C. M. (2002). Fitness enhancement and changes in body image. In T. F. Cash \& T. Pruzinsky (Eds.), Body image: A handbook of theory, research, and clinical practice (pp. 414-421). New York, NY: Guilford Press.

McLean, S. A., Paxton, S. J., \& Wertheim, E. H. (2011). A body image and disordered eating intervention for women in midlife: A randomized controlled trial. Journal of Consulting and Clinical Psychology, 6, 751-758. doi:10.1037/a0026094

Mond, J. M., Hay, P. J., Rodgers, B., Owen, C., \& Beaumont, P. J. V. (2004). Validity of the Eating Disorder Examination Questionnaire (EDE-Q) in screening for eating disorders in community samples. Behaviour Research and Therapy, 42, 551-567. doi: 10.1016/S00057967(03)00161-X

Moradi, B., \& Huang, Y. (2008). Objectification theory and psychology of women: A decade of advances and future directions. Psychology of Women Quarterly, 32, 377-398. doi:03 616843/08
Muth, J. L., \& Cash, T. F. (1997). Body image attitudes: What difference does gender make? Journal of Applied Social Psychology, 27, 1438-1452. doi:10.1111/j.15591816.1997.tb01 607.x

Myers, T. A., \& Crowther, J. H. (2007). Sociocultural pressures, thin-ideal internalization, self objectification, and body dissatisfaction: Could feminist beliefs be a moderating factor? Body Image, 4, 296-308. doi:10.1016/j.bodyim.2007.04.001

Noll, S. M., \& Fredrickson, B. L. (1998). A meditational model linking self-objectification, body shame, and disordered eating. Psychology of Women Quarterly, 22, 623-636. doi:10.1111/j.14716402.1998.tb00181.x

Olivardia, R., Pope, H. R., Borowiecki, J., \& Cohane, G. H. (2004). Biceps and body image: The relationship between muscularity and self-esteem, depression, and eating disorder symptoms. Psychology of Men and Muscularity, 5, 112-120. doi:10.1037/ 15249220.5.2.11

Paxton, S. J., Neumark-Sztainer, D., Hannan, P. J., \& Eisenberg, M. E. (2006). Body dissatisfaction prospectively predicts depressive mood and low self-esteem in adolescent girls and boys. Journal of Clinical Child and Adolescent Psychology, 35, 539-549. doi: 10.1207/s15374424jccp3504_5

Pennebaker, J. W. (1997). Writing about emotional experiences as a therapeutic process. Psychological Science, 8, 162-166. doi:10. 1111/j.1467-9280.1997.tb00403.x

Peterson, C. B., Crosby, R. D., Wonderlich, S. A., Joiner, T., Crow, S. J., Mitchell, J. E., ... le Grange, D. (2007). Psychometric properties of the Eating Disorder Examination-Questionnaire: Factor structure and internal consistency. International Journal of Eating Disorders, 40, 386-389. doi:10.1002/eat.20373

Pliner, P., Chaiken, S., \& Flett, G. L. (1990). Gender differences in concern with body weight and physical appearance over the lifespan. Personality and Social Psychology Bulletin, 16, 263-273. doi:10.1177/0146167290162007

Prichard, I., \& Tiggemann, M. (2008). Relations among exercise type, self-objectification, and body image in the fitness centre environment: The role of reasons for exercise. Psychology of Sport and Exercise, 9, 855-866. doi:10.1016/j.psychsport.2007.10.005

Quinn, D. M., Kallen, R. W., \& Cathey, C. (2006). Body on my mind: The lingering effect of state self-objectification. Sex Roles, 55, 869-874. doi:10.1007/s11199-006-9140-x

Roberts, T., \& Waters, P. L. (2004). Self-objectification and that "not so fresh feeling:" Feminist therapeutic interventions for healthy female embodiment. Women \& Therapy, 27, 5-21. doi: 10.1300/J015v27n03_02

Robins, R. W., Hendin, H. M., \& Trzesniewski, K. H. (2001). Measuring global self-esteem: Construct validation of a single-item measure and the Rosenberg Self-Esteem Scale. Personality and Social Psychology Bulletin, 27, 151-161. doi:10.1177/014616 7201272002

Rodin, J., Silberstein, L. R., \& Striegel-Moore, R. H. (1984). Women and weight: A normative discontent. In T. B. Sonderegger (Ed.), Nebraska symposium on motivation: Psychology and gender (Vol. 32, pp. 267-307). Lincoln, NE: University of Nebraska Press. 
Rosenberg, M. (1965). Society and the adolescent self-image. Princeton, NJ: Princeton University Press.

Schmitt, D. P., \& Allik, J. (2005). Simultaneous administration of the Rosenberg Self-Esteem Scale in 53 nations: Exploring the universal and culture-specific features of global self esteem. Journal of Personality and Social Psychology, 89, 623-642. doi:10.1037/00223514.89.4.623

Stephens, D. L., Hill, R. P., \& Hanson, C. (1994). The beauty myth and female consumers: The controversial role of advertising. The Journal of Consumer Affairs, 28, 137-153. doi:10.1111/j.17456606.1994.tb00819.x

Stevens, C., \& Tiggemann, M. (1998). Women's body figure preferences across the life span. The Journal of Genetic Psychology, 159, 94-102. doi:10.1080/00221329809596137

Stice, E. (2002). Risk and maintenance factors for eating pathology: A meta-analytic review. Psychological Bulletin, 128, 825-848. doi:10.1037//0033-2909.128.5.825

Stice, E., Trost, A., \& Chase, A. (2002). Healthy weight control and dissonance-based eating disorder prevention programs: Results from a controlled trial. International Journal of Eating Disorders, 33, 10-21. doi:10.1002/eat.10109

Tiggemann, M. (1992). Body-size dissatisfaction: Individual differences in age and gender, and relationship with self-esteem. Personality and Individual Differences, 13, 39-43. doi:10.1016/ 0191-8869(92)90215-B

Tiggemann, M. (2004). Body image across the adult life span: Stability and change. Body Image, 1, 29-41. doi:10.1016/S17401445(03)00002-0
Tiggemann, M., \& Lynch, J. E. (2001). Body image across the adult life span: Stability and change. Body Image, 1, 29-41. doi:10. 1016/S1740-1445(03)00002-0

Tiggemann, M., \& Williams, E. (2011). The role of selfobjectification in disordered eating, depressed mood, and sexual functioning among women: A comprehensive test of objectification theory. Psychology of Women Quarterly, 35, 66-75. doi:10. 1177/0361684311420250

Tolman, D. L., \& Debold, E. (1994). Conflicts of body and image: Female adolescents, desire, and the no-body. In P. Fallon, M. A. Katzman, \& S. Wooley (Eds.), Feminist perspectives on eating disorders (pp. 301-317). New York, NY: Guilford Press.

Tylka, T. L. (2006). Development and psychometric evaluation of a measure of intuitive eating. Journal of Counseling Psychology, 53, 226-240. doi:10.1037/0022-0167.53.2.226

Vaes, J., Paladino, M. P., \& Puvia, E. (2011). Are sexualized females complete human beings? Why males and females dehumanize sexually objectified women. European Journal of Social Psychology, 41, 774-785. doi:10.1002/ejsp.824

Webster, J., \& Tiggemann, M. (2003). The relationship between women's body satisfaction and self-image across the life span: The role of cognitive control. The Journal of Genetic Psychology, 164, 241-252. doi:10.1080/00221320309597980

Wood-Barcalow, N. L., Tylka, T. L., \& Augustus-Horvath, C. L. (2010). "But I like my body": Positive body image characteristics and a holistic model for young-adult women. Body Image, 7, 106-116. doi:10.1016/j.bodyim.2010.01.00 